\title{
Study on New-style Industrialization of Biomass Energy Equipment
}

\author{
Lei Liu ${ }^{1,2,3, a}$,Longjiang $\mathrm{Li}^{1,2,3, \mathrm{~b}^{*}}$,Shuo $\mathrm{Han}^{4, \mathrm{c}}$, Meng He $\mathrm{He}^{4, \mathrm{~d}}$ \\ ${ }^{1}$ Mining College, Guizhou University, Guiyang Guizhou ,550025, China \\ ${ }^{2}$ Guizhou engineering lab of mineral resource,Guiyang Guizhou,550025,China \\ ${ }^{3}$ GuiZhou Key Laboratory of Comprehensive Utilization of Non-metallic mineral resources, \\ Guiyang Guizhou, 550025 China \\ ${ }^{4}$ School of Chemistry and Chemical engineering, Guizhou University, Guiyang \\ Guizhou,550025,China

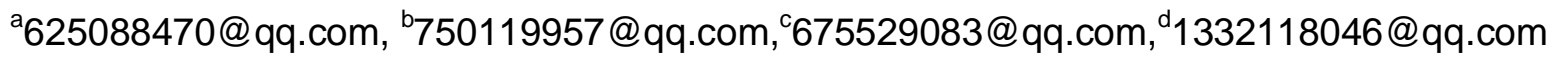

\begin{abstract}
Keywords: New biomass, wind and gas complementary, market-oriented, industrial equipment Abstract: This work is the scenery complementary gas of biomass energy -equipment industry which is mainly to complete the biomass energy equipment,in order to provide the conditions of production and service for new biomass energy device. At the same time, based on China's renewable energy development , current situation of market research and sales assessment, so as to conduct a feasibility analysis.Finally, the model of biomass energy could be realised Industrialization and service,and widely applied in city and rural area; the main technology is to set a system to take advantage the fan, solar panels and fermentation tank, which use the scenery complementary . So the wind, light and gas are maximizeed to use. New biomass device based on the existing in cities and rural towns. New conversion technologies are good for the development of the area, it can reduce emissions, protect the environment and realize sustainable development.
\end{abstract}

\section{The research background of new biomass energy equipment}

Energy is a important basis of the social economic development.It is not only important to the whole society, but also have big influence on the development of the economic.Biomass energy is generally regarded as the biggest renewable energy in the world.Biomass energy, as a important kind of the energies, is more and more paid attention by all countries.It is becoming a new industry which have big potential.Develop biomass energy can ease the nervous situation of the supply of the fossil energy and guarantee the security of a country.Nowadays, when the ecological environment is badder and badder, developing biomass energy is so necessary. The low cost of biomass energy make it suit for the remote and poor area.

\section{Domestic development status}

In recent years, the Chinese government attaches great importance to the development and utilization of biomass energy, adopt corresponding laws and regulations, and has achieved a high level of technological achievement, initially has formed the biomass industry. Especially in biogas technology, both in terms of total size or technological development levels, leads to the international advanced level. In terms of energy utilization of straw, biomass combustion generation also has a certain scale, mainly in the South. Our government attaches great importance to development and utilization of biomass energy, since in the 1970 of the 20th century, in 4 four consecutive "five-year plan" , the government researched and application of biomass energy utilization technologies as a key scientific and technological projects, the development and implementation of a series of study on biomass utilization projects and demonstration projects, which promoted the development of biomass energy industry in China.

\section{Foreign development status}

At present, many countries devote to develop renewable energy.Such as the development of sunshine in Japan, the energy farms in America and the Brazil's ethanol energy plan. So, it has great significance to develop biomass energy . Biomass energy technology and equipment has reached the degree of commercialization, and realized the scale of operation industry on abroad. The skill of 
biomass energy transfer to high-grade energy has developed considerable scale in America, Sweden and Austria. As a shortcut,they use the biomass energy to reduce dependence on the foreign oil and revitalize the rural economy,now the biomass energy in USA has overpassed the hydropower, become the largest renewable energy,take up more than $4 \%$ of the total energy consumption in USA.In Sweden,people rely on biomass energy as "farewell oil", and bio-gas car has spread all over the country.Over $60 \%$ heating relying on biomass fuel.Brazil succeed using on biomass energy to make up for the lack of oil .In 2009, sugarcane ethanol instead of gasoline 56\%. India and Japan have also formulated the strategy and measures actively, accelerate the development of biomass energy industry.

\section{Advantage of the small size of the biomass unit}

Small apartment is equipped with renewable biomass resource utilization equipment, it is through the freedom to switch temperature sensor gas detection and scenery to maximize wind, light, gas and energy supply in the process of realization of the benefits. Has certain advantages .

Biomass is a renewable resource, wind, solar and renewable energy are all rich in natural resources and can ensure the sustainable use of energy ; small apartment device uses wind and solar, according to the Guizhou mountain climate characteristics, not only the solar panels automatically greet light , track the sun ; and let the wind turbine can automatically improve the fan power generation capacity in a small amount of wind environment. It combined with each other to provide a steady stream of power . Biomass sulfur, nitrogen content is low, less generated during combustion sulfide, nitride ; efficient use of solid waste, urban waste is difficult to solve the problems piling up , avoid their burial, burning pollution, environmentally friendly cleaning produced ; in the absence of regional coal , biomass can take advantage of . Biomass energy is the world's fourth largest, behind coal, oil and natural gas. According to biologists estimated annual production of the Earth's land from 1000 to 125 billion tons of biomass ; marine production of 50 billion tons of biomass. The production of biomass energy is far more than the world's total energy demand, equivalent to 10 times the world's total energy consumption. Our country is an agricultural producing countries, rich source of biomass feedstock manufacturing

\section{China's biomass policy-oriented and technological innovation}

Development and utilization of biomass energy which is an important part of the development of circular economy, also, it is an important measure to promote rural development and farmers' income and an important task to foster and develop strategic emerging industries. In order to enhance the comprehensive utilization of biomass energy and improve the efficiency of biomass energy utilization, to better play the overall efficiency resources, economic, social and ecological, and promote the healthy development of biomass energy industry. The National Energy Board proposed the implementation of "The Twelfth Five-Year Plan for biomass energy development", its fundamental principles are: overall consideration comprehensive utilization; adapted to local conditions, Pluralistic Development; independent innovation, the scale development; government support, market driven.

To further expand the scope of support renewable energy resources, increase the support efforts to its utilization, improve the share of renewable energy in the consumption structure, making it possible to achieved 16 percent of China's total energy consumption of renewable energy in 2020; Further support the use of renewable energy in remote areas, release energy markets, enhance market competitiveness of manufacturing enterprises, and promote the development of renewable energy. Wherein, the development of biomass energy plans a target during the National Twelfth Five-Year Plan period. That is, to form a larger-scale biomass energy industry with initially realized the commercialization and utilization of energy use in electricity, heating and living in rural areas (the transport sector to expand the scale of alternative to petroleum fuels). With the significantly improvement of biomass energy utilization technologies, it appears a number of the new large-scale 
biomass energy firms with great technical innovation ability. Forming a relatively complete biomass energy industrial system.

\section{Application and extension}

Biomass energy is a new kind of clean energy, and can be used to generate electricity, combustion, treatment. Bio mass can has more advantages, specific performance in production and the using of process in the clean no pollution; development to area of using, can alternative wood, and coal, not renewable energy; elimination coal-fired produced of large ash, and carbon monoxide, and sulfur dioxide, and three oxidation sulfur, toxic gas and carcinogenic material; can processing rural organic life garbage, can effective to protection water, reduced pollution, can improved soil, increased soil organic matter.

At present domestic biomass production equipment type is unitary, and there are defects in the inlet and outlet temperature control, energy management, etc.. So the market in urgent need of a biomass fermentation device of improving its disadvantages. The biomass reaction device of the design can solve a series of problems. The reaction device is its small, position control is more convenient and easy to control temperature. Can be widely applied to rural and city biogas production, improve production efficiency, achieve the integration of biogas production product. It does not use any power equipment in the production process, is of great significance in energy conservation and emission reduction.

Biomass energy equipment is the basis and prerequisite for rapid development of biomass energy. In conditions of biomass energy industry faces a huge opportunity, biomass energy equipment also there will be more opportunities. According to characteristics of biomass at low cost and no pollution, today's society to promote development of rural and urban communities biomass generator, is expected in energy development and utilization of equipment and services which can make a breakthrough.

Certainly, in which most has the prospects for development region is the rural market small family continuous type constant temperature solar energy biology mass energy response installment product and the city plot city people unit building organic trash highly effective fermentation treating plant.Therefore, the marketing to its promotion also is the essential step. Total marketing strategy: The whole staff marketing with uses the marketing strategy which the direct sale and the channel marketing unify.In obtains under the government support, by opens the organization to the room the direct sale association primarily, retails for auxiliary, and gradually to OEM production development.

To product yieldly research: Using the market survey, according to the transportation environment, sideline product processing, the environmental protection, the personnel measures and so on the selection appropriate positions to use as the production.Conforms to the economical development path according to the market characteristic formulation, causes it to obtain the highest benefit. At the same time, the key city and the small and medium-sized town and cities also break through, the prioritize model project, forms the integrity the product and the service plan. The product adds the technical service the plan to have to provide for a long time, the purchase product on provides the technical guidance and the service for a long time, sets up the post-sale service station, the contrast similar product, has the service optimization, better promotion sale.The following product research needs to act according to the different allocated proportion the organic matter fermentation way to make the fermentation installment improvement. With the aid of the scientific research platform, the research organic matter methane fermentation mechanism, including the liquid-solid compared to, the biological mass energy composition, the fermentation mold mushroom spawn, the fermentation rule, has the plan to have the step instruction user better application equipment.The development circulation composite aircraft or the highly effective methane catalyst, the surface active agent or the solution ferments in the winter the low temperature fermentation question, enhances the methane to produce is mad rate.

The development demonstration project, forms the perfect product and the service plan, takes the successful case, the impetus product sale.Strives for the government cooperation, the street 
advertisement, the television advertisement, the network advertisement, visits the sales promotion, the mail sales promotion, the broadcasting station broadcasts, the network sales promotion, the factory visiting group, the exhibition way, multi-channel promotional material.

\section{Market analyses and cost analysis}

After market research, on the one hand kept covering totaled 750,000 acres of garbage in China, and one-fourth of the city and which has no suitable place to pile up garbage. Garbage disposal as an urgent issue of environmental governance agenda of Governments at all levels already mentioned. According to the total emissions of major pollutants deployed our province, some cities have begun to dismantle non-industrial production in coal-fired boilers in urban area. The MSW through composting. The other hand, I save some electricity, oil, gas, coal, heating and gas supply enterprises, due to the rise in fuel prices, there is an urgent need for clean, economical alternative fuels. But in rural areas, the available dedicated gas burning straw particle, by farmers with straw for pellet fuel as a way to reduce the financial burden of farmers, while greatly improving the rural environment and quality of life. Thus, large areas of biomass energy in China has a great market demand. Due to the location of Guizhou, has the power to make the distributors and companies cooperate with each other to break into the industry. Facilitate technological improvements.

Market localization for small family continuous type biology mass energy fermentation installment; Floats covers the type to live the material to tire of the oxygen digestion equipment; Nonmotile self-discharging -like constant temperature solar energy biology mass energy fermenting tank.At present, market share small family continuous type biology mass energy fermentation installment by occupation. The main market localization includes: City plot and general countrysides.

\section{Urban district}

he city plot is a latent huge stealth market, at present has not been developed.The city plot organic solid life trash at present main processing mode is pours into the trashcan to pull fills in buries, burning down. The organic life trash main processing mode disperses into the sewer pipe, disperses into the river, the river, the lake wave directly after sewage treatment plant simple processing.Not only this processing mode causes the serious pollution to the environment, moreover has wasted the resources.

Statistics have indicated, Guiyang each household may produce approximately the $1.5 \mathrm{~kg}$ solid organic waste every day, if will be able to solve the environment and the energy dual questions with these reject production methane.Installs a living thing intelligence fermentation equipment in city plot each unit then to solve this unit inhabitant's solid organic life trash and the sanitary sewage processing question.Along with the biological mass energy unceasing progress, city life trash biological chemistry processing gradually will develop, the city plot will be this company mainly sells the object .

\section{Rural marketing}

In recent years, biomass energy is distributed widely in the rural areas. The development of biogas industry is very wide, it can make processing of manure, straw and other organic waste without polluting, so as it can protect the environment,solve fuel and lighting problems and save energy. Under the call of the national policy on construction of new Socialist countryside and rural,the development and utilization of biomass energy has a broad prospect in China.

At present, the known biological mass energy fermentation device of rural household mostly builded by digging pond underground which uses the brick and the concrete.This way exists many disadvantages.Such as difficult to constructs the pond,the quality is uneven, can not be continuous charging,discharging management difficult and the gas production rate is low .The structure of the traditional biological mass energy fermentation device is made of feed house,sweat house and ejection house,its peak is slightly higher than the ground.The feed house and the ejection house of the biological mass energy fermentation device are located in the both sides of the device. So the device not only covers a big area,in and out of the material is inconvenient,but also has a unsatisfactory heat preservation effect, moreover,basically all biological mass energy fermentation device have no the 
stirring device and the biogas slurry surface is easily crusts.It has not been able to solve the discharging problem over the years.

\section{Market demands}

A market research shows that there is more than 2100 ton daily garbage in Guiyang, while the number of daily processing is just 1400 ton. According to the introduction made by the deputy director general of Guiyang Urban Administration,there is 1.97 million people and 1 city even 3 counties making the amount of garbage rang in 2100 to 2200 tons per day. This number is just from a ordinary statistics, which becomes more large and increases rapidly when festival days come.Besides, the account of garbage in Guiyang is increasing with the speed of $7.9 \%$ every year, catching up with the standard of Beijing. In other sides, there are many problems with Guiyang garbage management, such as weak awareness of public environmental protection single method of garbage management, unenlightened facilities and short of money and so on.Aiming at these problems, the government can improvement the situation of garbage management in Guiyang by strengthening publicity and the research of technology of garbage management, boosting the construction of management system, making laws and regulations even other ways, in order to make very policy true, boost the work of city garbage management,boost our city's sustainable development. At present, there are only two refuse landfills having the ability of garbage disposal in Guiyang, Gaoyan and Proportion dam in Wudang. Gaoyan Wudang refuse landfill's quantity of garbage disposal is 800 tons per day, Proportion dam refuse landfill's quantity of garbage disposal is 600 tons per day. The growing amount of garbage if more than beyond there current capacity. The amount of garbage which can used in fermentation is just about 500 tons, getting rid of recoverable garbage and inorganic garbage and non-fermentable garbage. There is about 1000 tons garbage is being making by the cities and towns around Guiyang,with 100 tons fermentable organic garbage.The following table1 shows the constitution of city organic garbage.

Table 1 city organic life trash component

\begin{tabular}{|c|c|c|c|c|c|c|}
\hline Constituent & Carbohydrates & Fat & Protein & Oil & Dross & Other \\
\hline Content $\%$ & $27-37$ & $18-22$ & $8-11$ & $3-7$ & $20-29$ & $7-9$ \\
\hline
\end{tabular}

From this may see the city to have very many trash to treat processing.Guiyang has over a thousand plots, unit building quantity must up to ten thousand, estimates popular rate $35 \%$, then will sell at least 3500, the inhabitant unit building organic trash highly effective fermentation treating plant will be decided 1100 initially.

Rural market demand: The Xiuwen County 288,000 people, the Xifeng County 246,000 people, the Kaiyang County 419,000 people, the Qingzhen city 498,000 people, except the county seat population and the outbound personnel family, the popular rate are decided $20 \%$. The conservative estimate sales volume is 28000 , the small family continuous type biology mass energy fermentation installment is decided 6000 initially.Therefore, company's establishment will bring the very big benefit.

Wind biomass products are environmentally friendly, energy-saving device as the main fermentation realized zero pollution in rural, city, market position, including the vast number of rural and urban residents. Its products and has a relative competitive advantage compared to similar products. Customer purchase criteria for this type of product is based on product availability, pollution-free, safe, and long benefits. Company plans in the preliminary stage, launched the free trial product, with the corresponding explanations and specialized technical staff assistant, enable customers to understand the high, and interest in the product.

\section{Summary}

Through the above analysis and the current market research survey, the research of biomass energy equipment can realize the industrialization and marketization in our province. Scenery complementary systems can take good use of wind, light and gas in supplement. Which solve the 
problem of serious environmental pollution,rubbish piled up and high cost of power generation in our province. Without the aid of any power devices in the application process, it has important significance in the aspect of energy saving and emission reduction.

\section{Acknowledgements}

This research was supported by Science and Technology Bureau of Guiyang City Industrial Relations Project of "The research and demonstration of new rural scenery continuous gas complementary biomass fermentation device key technology",the contract number of the project:NO.Building Division Contract [2011205] 4-02 .

\section{References}

[1] Lu Sa. The entire province sixth census main data bulletin issued, Guiyang Daily (A01) 2011-05-11.

[2] Ji Xianbing, Chen Yinxia. Guiyang life garbage disposal present situation and countermeasure research country environment administrative cadre institute journal in 201301 issues.

[3] Li is fragrant. Renewable energy electricity generation development present situation and prospect electric power journal F426.61 in 200801 issues.

[4] Wang Jiuchen, Dai Lin. Chinese biology mass energy industry development present situation and trend analysis agricultural engineering 2007 years 09 issues.

[5] Gao Hai Tao. The wind can - the solar energy - methane integrative system performance research TK513; TK6; TK83 Lanzhou University of Science and Technology 2003.

[6]Wang Yu. The scenery supplementary electricity generation control system research and develops Tianjin, Hefei Industrial university TM614; TM615 2004-12-01.

[7]Cai Chaoyue, Xia Lixin. The scenery supplementary generating system and develops( the J) mechanical and electrical information 2009(24).

[8] Constitutions live, Shen Jimin, severe great, solves. City life garbage disposal handling present situation analysis. Security and environment journal in 200304 issues.

[9] Min Qingwen, Pei dawn Philippines, Yu Weidong. Our country town refuse and processing present situation, question and countermeasure( J) urban environment and city ecology. 2002(06). [10] National Energy Bureau, biological mass energy development “35” plan. 